\title{
ARQUITETURA MODERNA EM MADEIRA: A CASA DO ARQUITETO E ESCULTOR ABRÃO ASSAD
}

\section{FELIPE TAROH INOUE SANQUETTA}

Faculdade de Arquitetura e Urbanismo da Universidade de São Paulo - Rua do Lago, 876 - Butantã, São Paulo - SP, 05508-080

https://orcid.org/0000-0003-4771-3588

Email: sanquetta@usp.br

\section{RESUMO}

Abrão Assad (1940-), arquiteto e escultor, contribuiu para o desenvolvimento da arquitetura e da arte moderna em Curitiba. Este trabalho tem como objetivo a documentação historiográfica e a realização de análise descritiva do projeto arquitetônico da residência de seu uso próprio. Concebida em 1979 por Assad, a casa está situada em um grande terreno circundado por um bosque nativo e se caracteriza pelo uso de componentes estruturais em madeira. Além da materialidade, a obra também se destaca pelo partido arquitetônico adotado, solução que remete ao sistema Dom-ino de Le Corbusier e as "casas apartamento" da Escola Paulista. O artigo se estrutura inicialmente com uma breve descrição sobre o processo de inserção dos conceitos modernos na arquitetura de Curitiba, a biografia do arquiteto, suas referências e outros projetos realizados. Para a documentação da obra, os procedimentos adotados se apoiaram na bibliografia existente e posteriormente na elaboração do redesenho do projeto original por meio de plantas, cortes e pelo uso de isométricas/diagramas para análises. Em uma segunda parte, são apresentadas imagens ainda não publicadas e que foram cedidas pelo acervo do arquiteto.

Palavras-chave: Arquiteto Abrão Assad. Arquitetura moderna em Curitiba. Arquitetura moderna em madeira.
Recebido: 24/10/2020

Aprovado: 26/10/2021

\section{ABSTRACT}

Abrão Assad (1940-), architect and sculptor, contributed for the development of architecture and modern art in Curitiba. This work aims to provide historiographical documentation and conduct a descriptive analysis of the architectural design of his residence. Constructed in 1979 by Assad, the house is located on a large plot surrounded by native forest and is characterized by the use of structural wooden components. In addition to materiality, the work also stands out for the architectural decision adopted, a solution that refers to the Dom-ino system of Le Corbusier and the "apartment houses" of the Escola Paulista. The article is initially structured with a description of the insertion of modern concepts in the Curitiba's architecture, the architect's biography, his references and other projects carried out. For the project documentation, the procedures adopted were based on the existing bibliography and afterwards on the digital redesign of the original design through plans, sections and the use of isometrics/diagrams for analysis. In a second part, images that have not yet been published and that were provided by the architect's collection are presented.

Key words: Architect Abrão Assad. Modern architecture in Curitiba. Modern architecture in wood. 


\section{INTRODUÇÃO}

Este trabalho tem como objetivo a documentação historiográfica e a realização de análise descritiva do projeto arquitetônico da residência do arquiteto e escultor Abrão Assad na cidade de Curitiba.

Inicialmente, realiza-se uma breve introdução do ideário moderno na capital paranaense, até o momento da formação acadêmica do arquiteto. Em seguida, é apresentada uma biografia do mesmo, seus feitos profissionais e principais obras. Por fim, são expostos os dados coletados, com a apresentação do redesenho vetorizado do projeto original, realizado a partir de levantamento in loco das informações e a apresentação de fotografias da montagem da obra e de sua conclusão.

Para o referencial teórico, o trabalho se apoiou sobretudo em três autores: Alberto Xavier (1986), Paulo Pacheco (2010) e Cristiane Pereira (2012).

O primeiro autor reúne em sua publicação as obras mais representativas da arquitetura moderna em Curitiba, fazendo citação à casa de Assad. Porém, esse trabalho se limita a uma breve descrição do projeto e à apresentação de plantas simplificadas e duas fotografias externas.

O segundo autor, em sua tese, apresenta o que chamou de "Arquitetura do Grupo Paraná", as obras mais representativas de uma geração de arquitetos, com um recorte temporal de 1957-1980. Esse trabalho apresenta praticamente os mesmos elementos de Xavier (1986), incorporando novas, mas poucas informações e fotografias.

O terceiro autor em sua dissertação, aborda o projeto pelo ponto de vista da sustentabilidade, apresentando informações de caráter mais técnico. Apesar disso, não aborda a documentação e não analisa o projeto arquitetônico propriamente.

Com isso, neste trabalho, espera-se complementar as informações disponíveis sobre o projeto, com um outro ponto de vista em relação às publicações anteriores, apresentando informações sobre a sua concepção, construção e espacialidade, que possam fomentar o estudo desse arquiteto e sua obra.

\section{ARQUITETURA MODERNA EM CURITIBA}

Durante os anos 1930, enquanto era iniciada a introdução dos conceitos modernos na arquitetura da cidade do Rio de Janeiro, se consolidava o repertório do que seria reconhecido como a imagem da arquitetura moderna brasileira. Esses eventos aos poucos ecoavam em outras regiões do país. Em Curitiba, somente se tinha contato com projetos de expressão moderna por meio de algumas obras de Frederico Kirchgässner (SANTOS \& ZEIN, 2009).

Somente nas décadas de 1940-50 que a arquitetura moderna começou a se tornar mais presente na cidade, pelas obras relevantes dos "engenheirosarquitetos", como o Teatro Guaíra, a Rodoferroviária de Curitiba e o Centro Politécnico da Universidade Federal do Paraná (UFPR) de Rubens Meister, as residências de Ayrton "Lolô" Cornelsen e os edifícios de Elgson Ribeiro Gomes. Projetos que tinham em comum a racionalidade construtiva e o uso do concreto armado (GNOATO, 2009).

Paralelamente, as obras públicas para a comemoração do Centenário de Emancipação política do estado do Paraná nos anos 1950 para o Centro Cívico de Curitiba no governo de Bento Munhoz da Rocha, representaram a materialização do movimento moderno arquitetônico na escala da cidade, liderados por David Azambuja, arquiteto paranaense cuja formação e obra tinha maior influência da linguagem moderna carioca (SANTOS \& ZEIN, 2009, p. 04).

As obras do arquiteto curitibano radicado em São Paulo, João Batista Vilanova Artigas, na cidade de Londrina, no norte do estado foram outro acontecimento que reverberou na capital paranaense (GNOATO, 2009, p. 57). 
O evento que promoveu grande transformação no cenário arquitetônico em Curitiba foi a criação do primeiro curso de arquitetura no estado, na Universidade Federal do Paraná (UFPR) em 1962. A fundação de escolas foi um fator significativo para a disseminação dos valores da arquitetura moderna pelo país. Para a formação do corpo docente, foram convocados jovens arquitetos formados nos grandes centros (São Paulo, Rio de Janeiro, Belo Horizonte e Porto Alegre) e em composição com alguns dos engenheiros-arquitetos curitibanos (SEGAWA, 1998, p. 131).

Esse processo de troca de experiências e conhecimentos por parte dos profissionais de outras regiões resulta em um processo de modernização e uniformização de valores culturais e técnicos via arquitetura (SEGAWA, 1998, p. 130).

Na UFPR, boa parte dos primeiros professores veio de São Paulo: José Maria Gandolfi, Joel Ramalho Júnior, Luiz Forte Netto, Roberto Luiz Gandolfi, graduados pela Universidade Presbiteriana Mackenzie. Esse grupo paulista do corpo docente e a proximidade entre os estados tornou intenso o intercâmbio e a influência nos novos profissionais (SEGAWA, 1998, p. 133).

O debate sobre as ideias modernas se tornou pauta do novo curso, cujos fundamentos vinham de conceitos corbusianos derivados das interpretações e reflexões de Lúcio Costa sobre a arquitetura. E o ensino de projeto originou um novo modo de pensar e do fazer arquitetônico. Em paralelo, eram construídas muitas obras relevantes dos arquitetos paulistas recém-migrados na cidade (SANTOS \& ZEIN, 2009, p. 05).

A primeira turma do curso de arquitetura e urbanismo da UFPR era composta por três grupos. O primeiro, composto por engenheiros recém-formados que puderam ingressar no curso e se formar em menos tempo; eram membros desse primeiro grupo: Jaime Lerner, Lubomir Fiscinski, Alfred Willer, Henrique Panek, Jaime Wassermann. O segundo grupo era formado por estudantes de engenharia que migraram para o curso de arquitetura; faziam parte desse grupo nomes como: Domingos Bongestabs e Rafael Dely. Por fim, o grupo de novos alunos regulares era composto por alguns nomes como Manoel Coelho, José Sanchotene, Oscar Mueller, Júlio Pechman e Abrão Assad (BERRIEL \& SUZUKI, 2012).

\section{O ARQUITETO-ABRÃO ANIS ASSAD}

Abrão Anis Assad nasceu em 1940 na cidade de Curitiba. Com interesses diversos, acaba se envolvendo em diferentes campos de atuação. A começar pela sua formação: possui graduação em Escultura pela Escola de Música e Belas Artes do Paraná (EMBAP), em 1962, em Ciências Econômicas, em 1964, e em Arquitetura e Urbanismo, em 1967 (na que é considerada a primeira turma regular do curso), ambas pela Universidade Federal do Paraná (UFPR). Apesar manter diversas ocupações paralelamente, devido às suas habilidades manuais e artísticas, ainda conseguiu fazer parte das equipes paranaenses que participavam de concursos de projetos de arquitetura, tendo sido premiado em diversos certames nacionais (PACHECO, 2010, p. 395):

- $1^{\circ}$ lugar no Concurso do Monumento à Fundação da Cidade de Goiânia (1964);

- $2^{\circ}$ lugar no Concurso da Sede do Tênis Clube de Presidente Prudente (1966);

- $2^{\circ}$ lugar no Concurso do Mercado Central de Porto Alegre (1967);

- $1^{\circ}$ lugar no Concurso do Edifício sede da Petrobrás no Rio de Janeiro (primeira etapa em 1967/ segunda etapa em 1968);

- $3^{\circ}$ lugar no Concurso da Biblioteca Central da Bahia (1968).

Assad participou do VIII Congresso Internacional de Arquitetura da União Internacional dos Arquitetos (UIA), na cidade de Paris, em 1965. Fez parte do grupo que foi selecionado para representar a Arquitetura do Brasil na $6^{\mathrm{a}}$ Bienal de Paris, em 1969, e da direção do Instituto dos Arquitetos do Brasil (IAB), ficando responsável pelo Setor de Artes Plásticas, em 1970 (MURÁ, 2018). 
Profissionalmente, atuou no Instituto de Pesquisa e Planejamento Urbano de Curitiba (IPPUC), órgão que ganhou notoriedade pelas intervenções de vanguarda na cidade. Na oportunidade, desenvolveu, em 1972, o projeto de "Pedestrialização da Rua XV de Novembro" em Curitiba. Projeto pioneiro de transformação de uma via central e movimentada da cidade em calçadão/via pública, com a implantação de mobiliário, equipamentos de lazer e estar (ROMANÓ, 2018).

Ainda, esteve também envolvido com os projetos de espaços e edifícios públicos na cidade, como a recuperação do Teatro Paiol, a Rua 24 Horas, o Jardim Botânico, a Pedreira Paulo Leminski, a Ópera de Arame, entre outros. Outro projeto de Assad foi o das estações tubo do transporte coletivo de Curitiba, os quais se tornaram um símbolo da cidade e que recentemente fizeram parte da exposição "Infinito Vão - 90 Anos da Arquitetura Brasileira", realizada na Casa da Arquitectura em Matosinhos, Portugal (MURÁ, 2018).

Nos anos 70, também participou da Comissão de Estruturação do Centro de Criatividade do Parque São Lourenço e dirigiu o Centro de Criatividade de Curitiba. Além disso, desenvolveu carreira acadêmica junto aos cursos de Arquitetura e Urbanismo da UFPR e PUC/PR, Escultura da EMBAP, e Escultura e Modelagem na Escola Museu Alfredo Andersen. Como artista, desenvolveu esculturas e painéis para diversos edifícios públicos e privados.

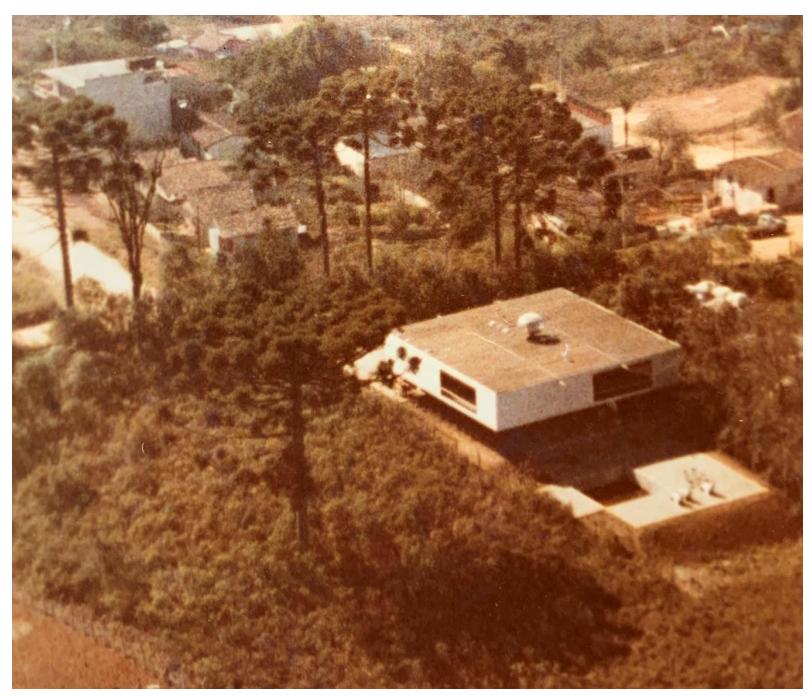

O PROJETO - ARQUITETURA, ARTE E TECNOLOGIA

Ficha técnica

- Autor: Arquiteto Abrão Assad;

- Cliente: Abrão Assad e família;

- Data do projeto: 1979 (PEREIRA, 2012);

- Localização: Rua Francisco Caron 1, Pilarzinho, Curitiba/Paraná (XAVIER, 1986);

- Principais publicações: PACHECO (2010), PEREIRA (2012), XAVIER (1986);

- Área do terreno: $15.000 \mathrm{~m}^{2}$ (PACHECO, 2010, p. 395);

- Área construída: $410 \mathrm{~m}^{2}$.

Após estar envolvido em projetos públicos por meio de sua atuação junto às equipes paranaenses em concursos ou junto ao IPPUC, Assad desenvolveu o projeto para a sua residência, em 1979.

Para esse projeto, o arquiteto não desenvolveu peças gráficas, somente uma maquete esquemática que auxiliava o canteiro de obras, no qual esteve presente (PEREIRA, 2012, p. 104). Como é evidente sua predileção pela prática, participou ativamente da construção da mesma, assim como ocorreu na implantação do projeto de Pedestrialização da Rua XV. Portanto, fez parte dessa etapa do estudo a realização do levantamento de 


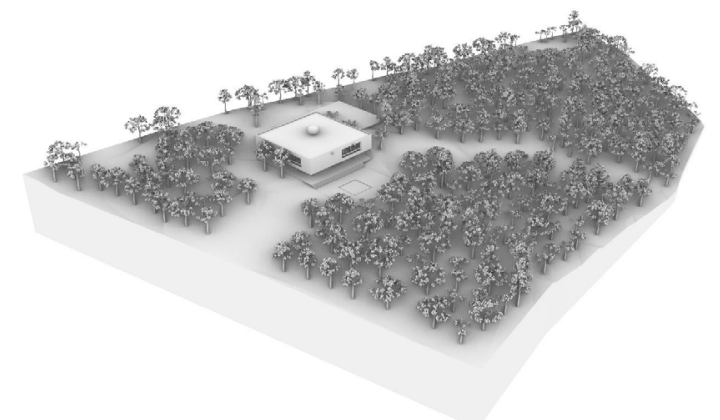

Figura 2 - Perspectiva aérea da Casa Abrão Assad. Fonte: Desenho do autor.

informações existentes sobre as plantas da casa, como no trabalho de Alberto Xavier (1986), e a posterior coleta de dados in loco, para o seu redesenho digital, assim como um modelo tridimensional.

Localizado no bairro Pilarzinho, o terreno de aproximadamente $15.000 \mathrm{~m}^{2}$ de área, na época era uma região distante do centro, composto por chácaras de imigrantes e com a presença de bosque nativo (PACHECO, 2010, p. 395).

A casa "evidencia o caráter especialíssimo com que foi concebida e em toda sua plenitude, o domínio artesanal que o arquiteto/escultor tem do emprego da madeira" (XAVIER, 1986, p. 229). Portanto, pode-se considerar como um espaço de experimentação e liberdade ao arquiteto.

O partido adotado remete ao sistema Dom-ino, o qual eleva o corpo principal da casa sob pilotis, tipologia adotada também nos projetos de "casas apartamento" pela Escola Paulista (PACHECO, 2010, p. 396). Portanto, a estrutura independente é formada por nove pilares distribuídos em uma modulação de 6,00 m. Cada um desses pilares é composto por 4 troncos roliços de eucalipto tratado que eram antigos postes de energia elétrica. A justaposição desses apoios permite engastar as vigas com pinos de aço, que também são o mesmo componente dos pilares, em ambos os sentidos da malha, conforme se observa na Figura 3.

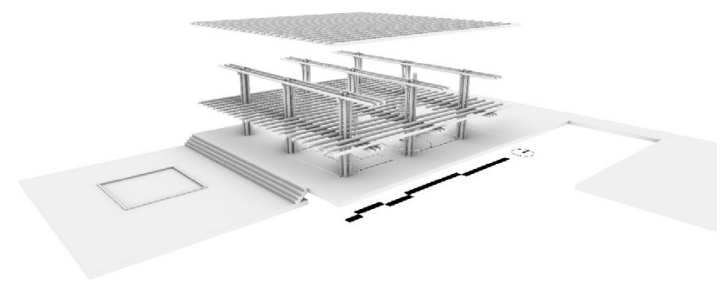

Figura 3 - Diagrama estrutural da Casa Abrão Assad. Fonte: Desenho do autor.

O volume elevado prismático de planta quadrada de aproximadamente $18,00 \mathrm{~m} \times 18,00 \mathrm{~m}$, acomoda balanços periféricos à estrutura, que geram espaços de abrigo e circulação no térreo. É conformado como uma caixa opaca, com somente uma abertura em cada fachada, a qual é revestida por chapas de alumínio.

Quanto ao programa, no térreo aberto somente permanece o hall de acesso, um pequeno apartamento de serviço e um abrigo para parte da coleção de carros antigos do arquiteto. No pavimento superior, o acesso social se dá por uma escada helicoidal e o acesso de serviço por uma escada interna. As duas estão junto ao núcleo servidor, portanto, a estratégia libera todo o perímetro e fachada para acomodação das áreas sociais e dormitórios, que são conformados por painéis leves com desenho orgânico, gerando espacialidades arredondadas em planta, estratégia recorrente na obra do escritório Forte \& Gandolfi, com o qual Assad colaborou em diversos trabalhos. Cada fachada recebe uma única abertura recuada, que permite gerando a varanda, com uma grande esquadria pivotante.

Do pavimento superior se tem acesso à cobertura aterraçada. Devido ao terreno estar localizado em uma das regiões mais altas da cidade, a casa está implantada a aproximadamente $1.000 \mathrm{~m}$ em relação ao nível do mar, o que propicia uma bela vista panorâmica desse mirante para a cidade, tendo como pano de fundo a serra do mar. 


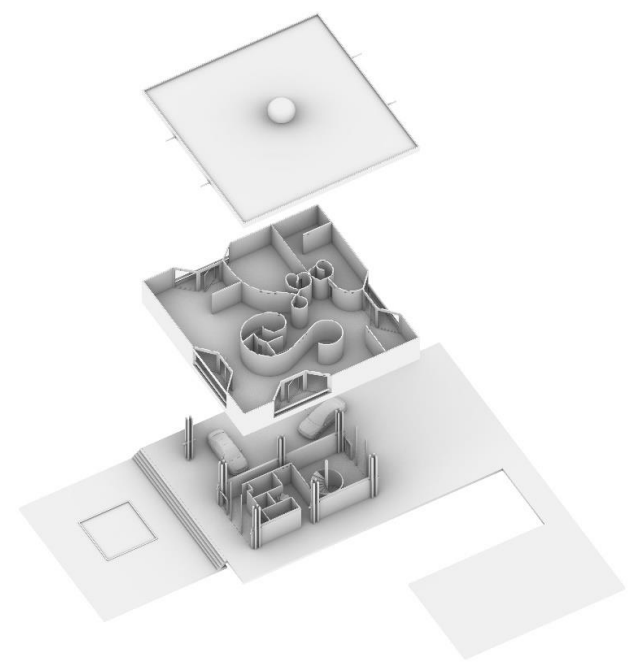

Figura 4 - Isométrica da Casa Abrão Assad. Fonte: Desenho do autor.

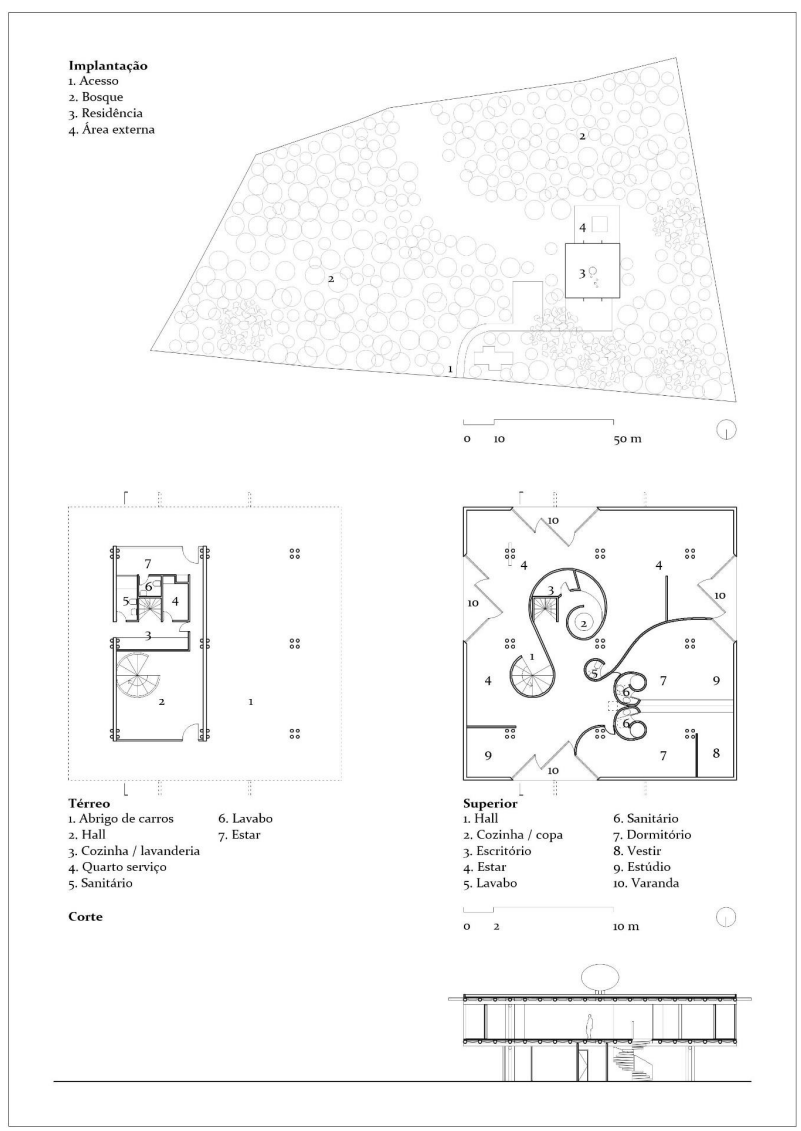

Figura 5 - Redesenho da Casa Abrão Assad. Fonte: Desenho do autor.
Construída, ou melhor, montada em apenas 4 meses, a materialidade principal da casa se dá pelo uso dos componentes brutos em troncos de madeira e pelos painéis das paredes internas, pisos e esquadrias. Mas também pelo revestimento em chapas de alumínio na fachada do volume suspenso e o uso de lã de vidro para isolamento no forro. O principal material, os antigos postes de madeira da cidade, foram utilizados em outras obras de arquitetura residencial, como na Residência Oswaldo Navarro (a qual segundo relato do arquiteto, teve semelhante processo projetual), e pública, como no projeto da Universidade Livre do Meio Ambiente - Unilivre, projeto de Domingos Bongestabs. Outro material que também tem origem de reaproveitamento é o piso do térreo e das áreas externas, composto de pedras de granito rosa que faziam a antiga pavimentação da Rua Inácio Lustosa, em Curitiba (GALANI, 2017).

\section{O REGISTRO - FOTOGRAFIAS DA OBRA}

Outra abordagem desse trabalho, em continuidade ao processo de documentação e análise do projeto, consiste em apresentar registros fotográficos realizados pelo arquiteto Abrão Assad durante a construção e inauguração da obra de sua residência.

Essa documentação ganha importância, considerando que o arquiteto não realizou qualquer documentação gráfica para a execução do projeto. Portanto, não sendo no papel, foi no canteiro que houve a materialização dos seus pensamentos. Além disso, se tratando de um artista, cuja obra passa por esculturas, painéis, desenhos e pinturas, aqui em suas fotografias podemos ver uma outra obra de Assad, sendo representada por ele mesmo.

A representação em fotografias de câmera analógica traz em algumas dessas imagens, a montagem dos componentes estruturais em madeira que compõem, com as araucárias do terreno, uma imagem de dissolução da estrutura da casa. 
Um aspecto relevante que pode-se notar nessa construção é o fato de as lajes serem pisos leves, constituídas por tábuas de madeira imbuia, com encaixe macho-fêmea e o forro em lã de vidro ensacada (PEREIRA, 2012, p. 11). Portanto, conforme a Figura 6, somente se tem a percepção dos elementos estruturais, em que se nota os vãos que foram preenchidos posteriormente com seus devidos revestimentos.

Além disso, com o início da montagem da estrutura, ainda sem a laje de cobertura, não é direta a associação da imagem de como esse esqueleto estrutural se comportaria quando a obra fosse finalizada, como um prisma elevado do chão. Esse esqueleto acaba se assemelhando às casas térreas em madeira dos imigrantes europeus, ainda encontradas na cidade de Curitiba.

Enfim, são apresentadas imagens de um ensaio realizado pelo fotógrafo, arquiteto e amigo Mauro Magnabosco após a finalização da obra.

$\mathrm{Na}$ Figura 10, com a obra finalizada, uma fotografia que captura o olhar do artista, enquadrando elementos que fazem parte de sua vida. Em primeiro plano, ao lado esquerdo da imagem, pode-se observar um rosto em uma escultura em pedra e ao seu lado uma motocicleta da época. Um dos usos que Assad dá para o piloti da casa é o abrigo para seus veículos, colecionador de exemplares antigos. Ao fundo está a sua casa, uma obra com um partido arquitetônico muito claro, concebida pela mente e executada pelas mãos de um arquiteto cuja obra está relacionada com o contexto em que se insere e que representa a liberdade e experimentação desse arquiteto/escultor.

Na Figura 11, pode-se observar a casa já ocupada, sendo refletida pela água da piscina e algumas peças de mobiliário externo distribuídas pelo terreno, conformando espaços de convívio da família.

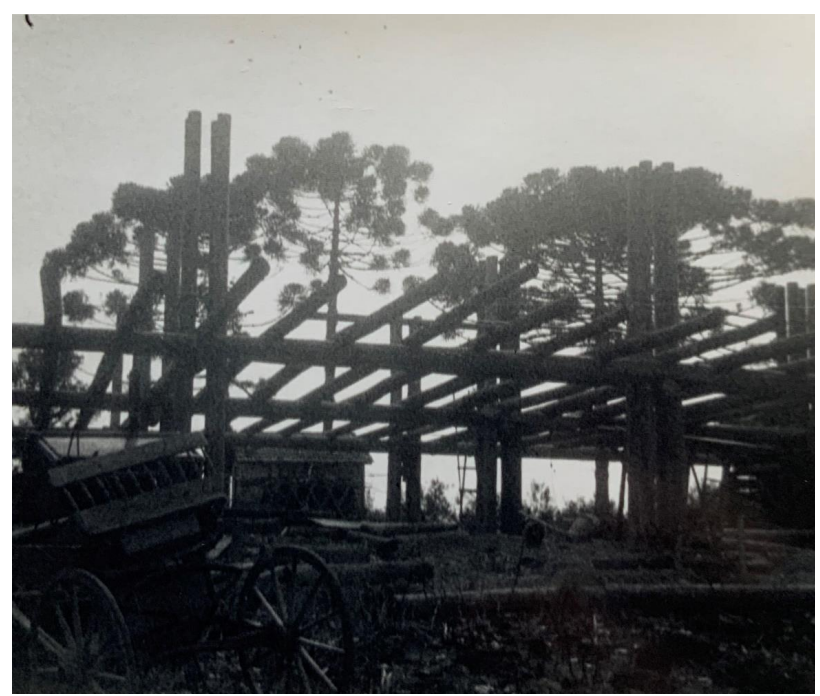

Figura 6 - Construção da Casa Abrão Assad. Fonte: Gentilmente cedida pelo acervo do arquiteto.
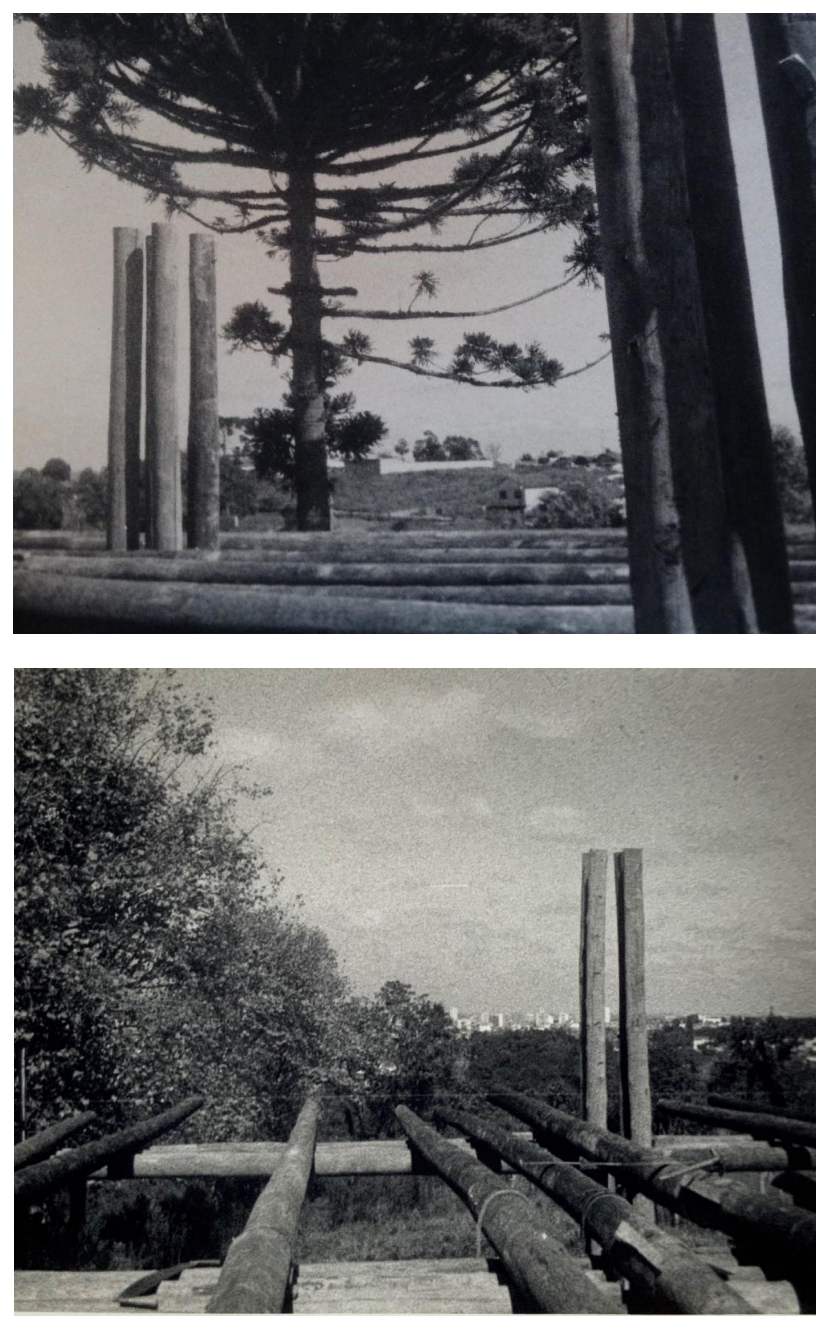

Figuras 7 e 8 - Construcão da Casa Abrão Assad. Fonte: Gentilmente cedida pelo acervo do arquiteto. 


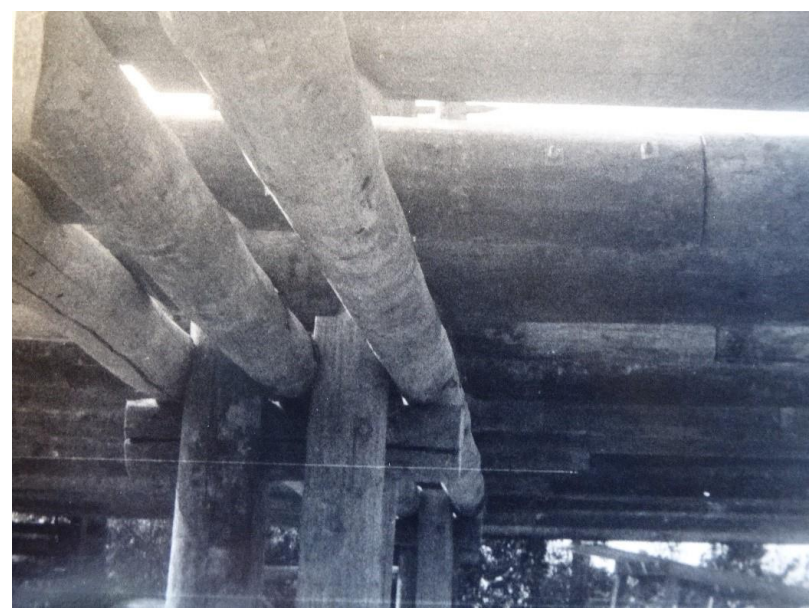

Figura 9 - Detalhe da construção da Casa Abrão Assad. Fonte: Gentilmente cedida pelo acervo do arquiteto.

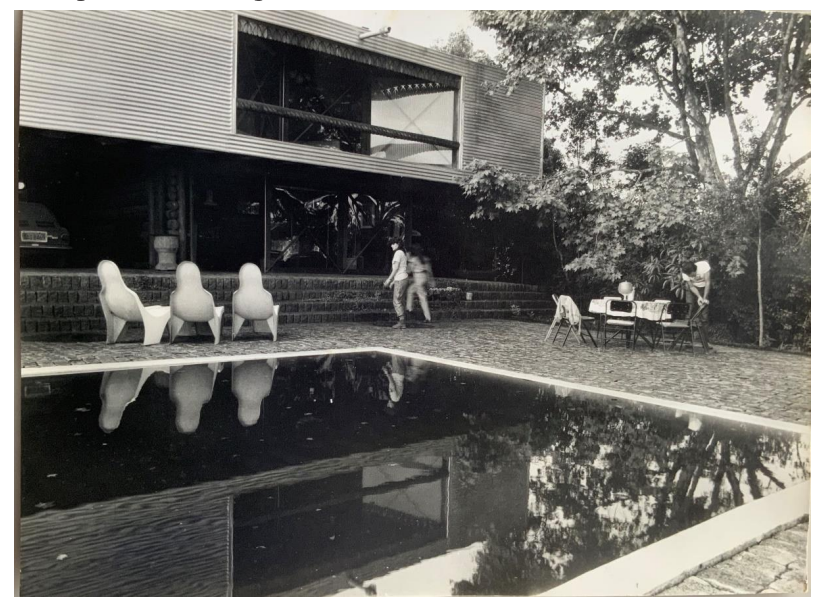

Figuras 11 - Casa Abrão Assad. Fonte: Mauro Magnabosco.

\section{CONSIDERACÕES FINAIS}

Observando a produção arquitetônica moderna brasileira, pode-se encontrar alguns exemplares de edificações construídas parcial ou totalmente em madeira. Obras como o Park Hotel São Vicente (1944-45) de Lúcio Costa, o Catetinho (1956) de Oscar Niemeyer, a Residência Artemio Furlan (1973) de Paulo Mendes da Rocha e até mesmo em parte nos pilares centrais da Residência Elza Berquó (1967) de Vilanova Artigas. Porém, esses projetos representavam certa exceção na obra desses arquitetos, considerando materiais e condições locais de determinado sítio e, em alguns casos, se a obra seria permanente ou temporária

Este trabalho se propôs a documentar de forma mais extensa o projeto em questão, apresentando um con-

$8 \mid \begin{aligned} & \text { Pos } \\ & \text { FAUUS }\end{aligned}$

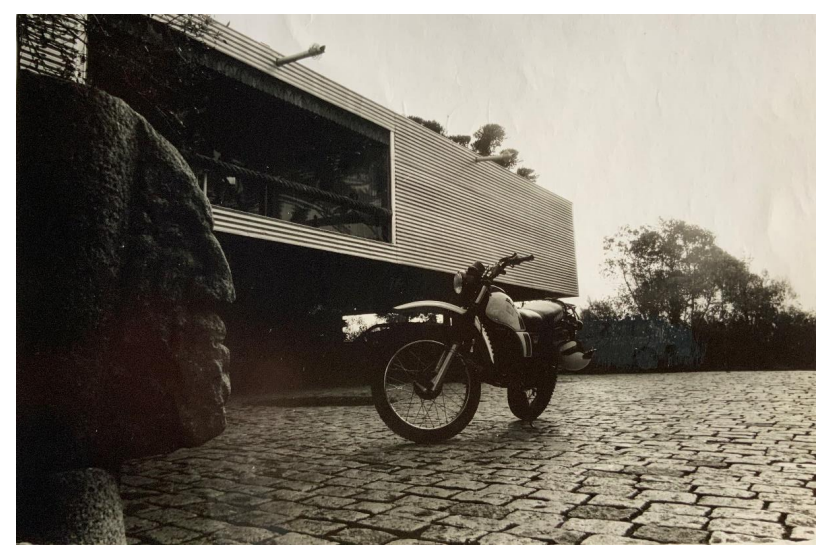

Figura 10 - Casa Abrão Assad. Fonte: Mauro Magnabosco.

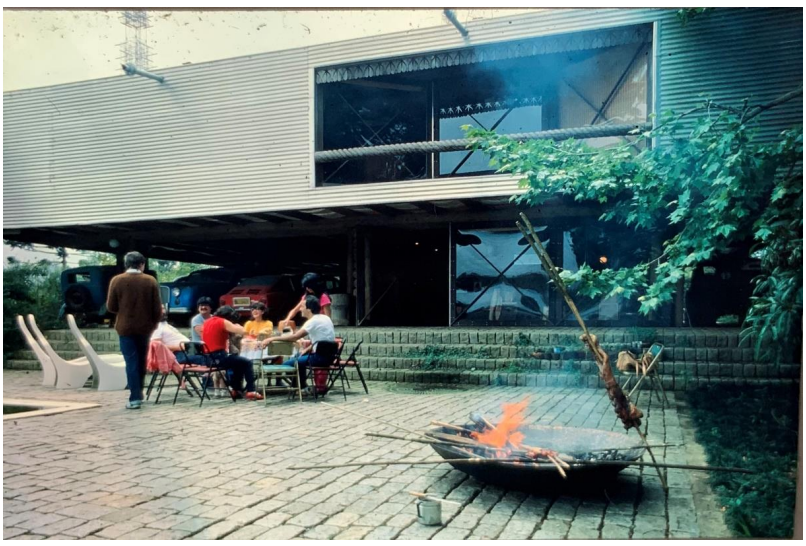

Figura 12 - Casa Abrão Assad. Fonte: Mauro Magnabosco.

junto desenvolvido de peças gráficas bidimensionais e tridimensionais do projeto, além de uma série fotográfica da época da construção e sua inauguração. Em paralelo, são apresentadas análises construtivas e espaciais do projeto.

Sugere-se, para futuros trabalhos, a complementação do estudo da diversa obra de Assad, extrapolando os projetos mais reconhecidos, para incluir até mesmo projetos privados e anteriores às contribuições de Assad em órgãos e obras públicas. Sugere-se, também, o estudo de outros exemplares de "Casa do Arquiteto", no Brasil e no exterior, que se caracterizam como um campo de liberdade projetual para seus autores, sendo um espaço propício para experimentações. 
A residência de Assad não se enquadra em conjecturas de uma linguagem arquitetônica. Como uma habitação unifamiliar projetada e construída para seu uso próprio, ele pôde fazer experiências que dificilmente seriam aceitas por um cliente convencional. É um projeto único, concebido pelo artista que tem uma obra explicitamente prática e que desfruta dos contornos e da vegetação de seu terreno.

Além disso, é notável a influência das diversas referências que Assad pode ter reunido em seu trabalho. Sobre o uso da madeira, recorda-se das casas históricas dos imigrantes europeus em Curitiba; os trabalhos em esculturas e painéis associam-se ao movimento artístico paranista e a resolução do partido arquitetônico é característica das residências da Escola Paulista. Lembrando que, mesmo que de forma mais indireta, Assad colaborou no escritório Forte \& Gandolfi, composto por arquitetos com formação e atuação ligados a São Paulo.

Ainda sobre o aspecto artístico do arquiteto, é notável sua capacidade de expressão em obras de diferentes materiais. Por exemplo, como consegue moldar barras e tubos metálicos para os desenhos das estações de transporte público. Sobre as estruturas em concreto armado aparente, realiza esculturas e painéis em grandes empenas e em saguões internos de edifícios. E sobre o trabalho em madeira, consegue tanto no arranjo de componentes estruturais, quanto entalhando painéis e formas escultóricas para gerar obras únicas. Essas atitudes, de certa forma, demonstram um modo de democratização da arte pelo artista, já que isso ocorre desde o desenho para um equipamento ou edifício público e até mesmo para uma residência.

Por fim, devido à obra ainda servir de residência ao arquiteto, as características originais se mantêm em sua maioria, embora seja um projeto elaborado e construído há quase 50 anos. A residência ainda surpreende pela sua qualidade espacial e seu sistema construtivo, tornando-a como um dos principais exemplares da arquitetura residencial curitibana dos anos 1970.

\section{REFERÊNCIAS:}

BERRIEL, Andrea Mercadante Stinghen; SUZUKI, Juliana Harumi. Memória do Arquiteto: Pioneiros da Arquitetura e do Urbanismo no Paraná. 2. ed. Curitiba: Editora UFPR, 2012.

GALANI, Luan. Conheça a cabana do homem que desenhou a Curitiba moderna. 2017. Disponível em: https:// www.gazetadopovo.com.br/haus/inspire-se/conheca-a-cabana-do-homem-que-desenhou-a-curitiba-moderna/ Acesso em: 20 set. 2020. Acesso em: 30 set. 2020.

GNOATO, Luís Salvador. Arquitetura do movimento moderno em Curitiba. 1. ed. Curitiba: Travessa dos Editores, 2009.

MURÁ, Aroldo. Abrão Assad mostra em Portugal revolução do mobiliário urbano de Curitiba. 2018. Disponível em: https://www.bandab.com.br/blog/aroldo/abrao-assadmostra-em-portugal-revolucao-do-mobiliario-urbano-decuritiba/. Acesso em: 15 set. 2020.

PACHECO, Paulo Cesar Braga. A Arquitetura do Grupo do Paraná 1957-1980. 462f. Tese (Doutorado em Arquitetura) - Programa de Pós-Graduação em Arquitetura FAUUFRS, Porto Alegre, 2010.

PEREIRA, Cristiane Martins Baltar. Arquitetura neovernacular em Curitiba: prospecções de suas contribuições para a sustentabilidade em três estudos de caso. 180f. Dissertação (Mestrado em Engenharia de Construção Civil) - Universidade Federal do Paraná, Setor de Tecnologia. Curitiba, 2012.

ROMANÓ, Maria Teresa. Desejo a você boas ideias. 2018. Disponível em: https://www.cultura930.com.br/desejo-avoce-boas-ideias/. Acesso em: 20 out. 2020

SANTOS, Michelle Schneider \& ZEIN, Ruth Verde. A moderna Curitiba dos anos 1960: jovens arquitetos, concurseiros, planejadores. In: $8^{\circ}$ Seminário DOCOMOMO BRASIL, 1 a 4 de setembro de 2009, Rio de Janeiro.

SEGAWA, Hugo. Arquiteturas no Brasil 1900-1990. 1. ed. São Paulo: EDUSP, 1998.

XAVIER, Alberto. Arquitetura Moderna em Curitiba. 1. ed. Curitiba: Editora Pini, 1986. 